\begin{tabular}{l|l|l|l} 
Cose Reports in & $\begin{array}{l}\text { Case Rep Neurol 2009;1:33-40 } \\
\text { Dol: } 10.1159 / 000226792\end{array}$ & Published online: July 22, 2009 & $\begin{array}{l}\text { @ 2009 S. Karger AG, Basel } \\
\text { ISSN 1662-680X } \\
\text { www.karger.com/crn }\end{array}$ \\
\hline
\end{tabular}

\title{
Excessive Daytime Sleepiness Is a Common Symptom in Fabry Disease
}

\author{
Thomas Duning ${ }^{a}$ Michael Deppe ${ }^{a}$ Simon Keller \\ Hagen Schiffbauer ${ }^{b} \quad J$ rg Stypmann ${ }^{c}$ Matthias Böntert ${ }^{\mathrm{a}}$ \\ Roland Schaefer $^{d}$ Peter Young ${ }^{\text {a }}$ \\ Departments of a Neurology, ${ }^{b} \mathrm{Clinical}$ Radiology, ${ }^{\mathrm{c} C}$ ardiology and Angiology, and \\ dInternal Medicine D (Nephrology), Hospital of the University of Münster,

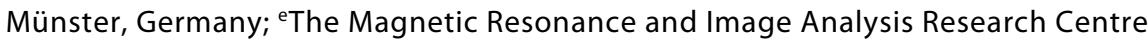 \\ (MARIARC), University of Liverpool, Liverpool, UK
}

\section{Key Words}

Fabry disease . White matter lesions - Excessive daytime sleepiness - Cheyne-Stokes respiration $\cdot$ Central apnea

\begin{abstract}
Fabry disease $(\mathrm{FD})$ is an X-linked lysosomal storage disorder characterized by a deficient activity of the enzyme a-galactosidase $A$, resulting in a vasculopathic involvement of various organ systems, e.g. cerebral structures. Marked cerebral vasculopathy with subsequent white matter lesions (WML) are a frequent finding in FD patients. Recent studies discussed an association between cerebral white matter changes and sleeprelated disturbances of breathing, which may lead to excessive daytime sleepiness (EDS). A 56-year-old Caucasian female FD patient with EDS was admitted to our sleep laboratory. Overnight polysomnography showed a Cheyne-Stokes respiration pattern with significant $\mathrm{O}_{2}$ desaturation. MR imaging revealed confluent WML including the brain stem, but no renal or cardiac involvement. We then evaluated the clinical data of 49 genetically proven FD patients ( 27 males; mean age 43 years) from our FD centre. With a frequency of $68 \%$, EDS exceeds the prevalence of other common symptoms of FD (angiokeratomas 61\%; acroparaesthesia 51\%; renal involvement 29\%; cardiac involvement $27 \%$ ), and the prevalence of chronic fatigue (48\%). EDS was independently associated with the physical component summary of the SF-36 data (corrected $\mathrm{R}^{2}=$ $-0.323, p<0.001)$. EDS and age explained a quarter of variance in mental component summary (corrected $\mathrm{R}^{2}=-0.253, \mathrm{p}<0.001$ ). We conclude that EDS is a common and underdiagnosed symptom in FD patients, accompanied by a significant impact on quality of life. EDS might be caused by central breathing disorders due to an affection of brain regions associated with respiratory control in FD.
\end{abstract}




\begin{tabular}{l|l|l|l} 
Cose Reports in & $\begin{array}{l}\text { Case Rep Neurol 2009;1:33-40 } \\
\text { Dol: } 10.1159 / 000226792\end{array}$ & Published online: July 22, 2009 & $\begin{array}{l}\text { @ 2009 S. Karger AG, Basel } \\
\text { ISSN 1662-680X } \\
\text { www.karger.com/crn }\end{array}$ \\
\hline
\end{tabular}

\section{Introduction}

Fabry disease (FD) is a $\mathrm{X}$ chromosome-linked inherited lysosomal storage disorder, due to partial or complete deficient activity of the enzyme a-galactosidase A caused by different X-chromosomal recessive mutations in the galactosidase gene. The decrease or absence of enzyme activity results in progressive accumulation of neutral glycosphingolipids in various organ systems, preferentially in the vascular endothelium and in smooth muscle cells, leading to microangiopathy, vessel occlusion, and ischemic tissue damage. In the first two decades, neuropathic pain, hypohydrosis, gastrointestinal symptoms and angiokeratoma are the clinical hallmarks [1]. Lifespan is shortened by late complications in adulthood, mainly caused by heart failure, renal dysfunction and cerebrovascular involvement (premature strokes and white matter lesions; WML) [2]. Clinical symptoms of FD are associated with significant impact on quality of life (QoL). The reduction in QoL in FD patients has been reported to be similar to that in AIDS patients [3].

Chronic fatigue is a frequent and early finding in FD patients with a significant impact on QoL. Although a common symptom in patients with chronic renal or cardiac dysfunction, chronic fatigue also appears in FD patients in whom renal or cardiac involvement has not been manifested [1]. Despite much research, the underlying pathophysiology of chronic fatigue still remains unknown.

Recent studies have demonstrated an association between cerebral white matter changes and sleep-disordered breathing, which may contribute to excessive daytime sleepiness (EDS) and subjective measures of daytime fatigue [4]. Severe progressive cerebral WML are frequent findings in FD and occur from an early age [2]. It may therefore be speculated that EDS is a frequent and under-diagnosed feature of FD, often falsely regarded as chronic fatigue.

We present an instructive case of EDS in a FD patient from our sleep laboratory with severe leukoaraiosis. To better determine the frequency of daytime sleepiness and its impact on QoL in FD, we consecutively evaluated the prevalence of EDS in a biochemically and genetically proven group of Fabry patients and assessed possible associations with multiple organ involvement.

\section{Case Report}

A 56-year-old Caucasian female FD patient was admitted to our sleep laboratory because of EDS. She had been taking enzyme replacement therapy (ERT) for 4 years. The diagnosis of FD was confirmed 4 years ago (by measurement of enzyme activity and molecular genotyping), but she had suffered from neuropathic pain and hypohidrosis since she was 15 . Echocardiograhy, kidney function tests, and routine biochemistry showed normal results, excluding severe cardiac or renal involvement. Further medical history and neurological examination were normal. Twenty-four-hour blood pressure levels were unrevealing (mean systolic/diastolic pressure $109 / 78 \mathrm{~mm} / \mathrm{Hg}$ ), with a mean arterial pressure of 99 $\mathrm{mm} \mathrm{Hg}$ and preserved nocturnal dipping. An EEG was normal, nerve-conduction velocities and extraand transcranial Duplex-ultrasonography showed no pathological findings.

The patient had a pathological Epworth Sleepiness Scale (ESS) score of 20 (normal <10) and a decreased multiple sleep latency test (MSLT) score of $4.6 \mathrm{~min}$ (normal $>10 \mathrm{~min}$ ). QoL was measured using the SF-36 health-related quality of life survey (http://www.sf36.org). Two summary scores are computed to reflect the physical or mental domains of health-related QoL: physical component summary (PCS) and mental component summary (MCS). QoL scores were markedly decreased (PCS: 33; MCS: 40). Polysomnography (overnight recording of sleep-wake cycles, electrocardiogram, electroencephalogram, electromyogram, oronasal air flow, chest wall and abdominal wall effort, and pulse oximetry) showed a Cheyne-Stokes respiration pattern characterized by periodic breathing with 


\begin{tabular}{l|l|l|l} 
Cose Reports in & $\begin{array}{l}\text { Case Rep Neurol 2009;1:33-40 } \\
\text { D01: 10.1159/000226792 }\end{array}$ & Published online: July 22, 2009 & $\begin{array}{l}\text { ○ 2009 S. Karger AG, Basel } \\
\text { ISSN 1662-680X } \\
\text { www.karger.com/crn }\end{array}$ \\
\hline
\end{tabular}

recurrent episodes of central apneas and hypopneas, alternating with hyperpneas and characteristic crescendo-decrescendo pattern of tidal volume (fig. 1, upper row). The central apnea/hypopnea index was $64 / \mathrm{h}$ (pathologic: $>10 / \mathrm{h}$ ) and respiratory arousal index was $46 / \mathrm{h}$ (pathologic: $\geq 5$ arousals per total sleep time), with repeated oxyhemoglobin desaturations up to $65 \%$. Subsequently, an MRI showed confluent hyperintense regions on FLAIR- and T2-weighted MRI sequences, and corresponding decreases of signal on T1-weighted images bilaterally in the cerebral white matter, with substantial brainstem involvement (fig. 1, lower row).

\section{Group Study}

After a comprehensive history by interview and searching of patients' documents, recording of clinical data of 49 FD patients (27 males; mean age 43 years; range 16-72 years) were assessed by a standardized questionnaire. To determine severity, patients were classified according to the previously described Mainz Severity Score Index (MSSI) [5]. The MSSI is then divided into severity bands of mild $(<20)$, moderate $(20-40)$ and severe $(>40)$ affliction. Furthermore, sleepiness, fatigue and QoL were measured using the ESS, Fatigue Severity Scale, and the SF-36. We compared the SF-36 scores of the present study with those of a large $(n=2911)$ German general population group [6].

For between-group comparisons, continuous variables were evaluated using the Student's t test. Correlations between the findings were tested by calculation of Pearson's correlation coefficient. To evaluate predictors of QoL, multiple stepwise regression analyses were conducted using the PCS and the MCS of the SF-36-survey as dependent variables. Demographic (age, gender, years of ERT, age of diagnosis) and clinical data (number of affected organs, MSSI-scores, and FSS- and ESS-values) were tested as independent variables.

\section{Results}

The average clinical stage of patients was mild to moderate, and male and female patients were comparably affected. The MSSI ranged from 0 to 51 (mean 15). Acroparaesthesia was present in 51\%. Neurological features were also the earliest to develop, beginning at an average age of 18 years. Cerebrovascular events were reported in $10 \%$ of cases. Cardiac abnormalities could be detected in $27 \%$. Abnormal renal function (proteinuria) was present in 29\%, but end-stage renal failure with the need of hemodialysis was present in only $6 \%$ of patients. Dermatological and gastrointestinal symptoms of FD were also common and reported by 61 and $41 \%$, respectively.

However, EDS and fatigue were the most common clinical symptoms. Pathological ESS $(\geq 10)$ and FSS $(\geq 5)$ scores were established in 68 and $48 \%$ of FD patients, respectively. Prevalence rates of individual clinical symptoms are shown in fig. 2.

Patients with pathological daytime sleepiness (mean ESS $14 \pm 3$ ) were slightly younger ( $42 \pm 12$ vs. $45 \pm 13$ years, $\mathrm{p}<0.007$ ) than patients without daytime sleepiness (mean ESS $7 \pm 3$ ), reported a longer total sleep time ( $7.35 \pm 1.08$ vs. $6.95 \pm 0.85 \mathrm{~h} /$ night, $\mathrm{p}<0.03)$, and had more difficulties in maintaining sleep $(19.3 \pm 4.8 \%$ vs. $14.4 \pm 3.9 \%, \mathrm{p}<0.005)$. The mean body mass index (BMI) was $27.6 \mathrm{~kg} / \mathrm{m}^{2}\left( \pm 6.0\right.$; normal $\left.<25 \mathrm{~kg} / \mathrm{m}^{2}\right)$ and did not differ between patients with or without pathological daytime sleepiness. Thirty-one percent of patients had a history of recurrent snoring, which was within the reported range of habitual snorers in the normal population, and $41 \%$ of FD patients reported recurrent napping during the day. Sixty-two percent of FD patients reported pathological fatigue without overlap of sleepiness, and only $11 \%$ reported pathological sleepiness without overlap of fatigue. Pearson's correlation analysis indicated a weak association $(r=0.18)$ between subjective fatigue and sleepiness in the total sample.

No significant correlations were found between clinical (MSSI and subscores, number of affected organs) or demographic (age, gender, years of ERT, age of diagnosis) data and 


\begin{tabular}{l|l|l|l} 
Cose Reports in & $\begin{array}{l}\text { Case Rep Neurol 2009;1:33-40 } \\
\text { D0l: } 10.1159 / 000226792\end{array}$ & Published online: July 22, 2009 & $\begin{array}{l}\text { @ 2009 S. Karger AG, Basel } \\
\text { ISSN 1662-680X } \\
\text { www.karger.com/crn }\end{array}$ \\
\hline
\end{tabular}

ESS or FSS scores. There were no significant differences among patients with or without renal or cardiac involvement or stroke with regard to ESS and FSS scores.

Compared to the general population, both females and males with FD showed consistently impaired QoL, as assessed using the SF-36 data (table 1). The only mean SF-36 scores above 67 were the role emotional score and the mental health score. In summary, the PCS and MCS were significantly decreased $(\mathrm{p}<0.01$ and $\mathrm{p}<0.05$, respectively), compared to a German reference population $(n=2,911)$. The PCS correlated inversely with the number of affected organs $(\mathrm{r}=-0.23 ; \mathrm{p}<0.05)$, the renal $(\mathrm{r}=$ $-0.34 ; \mathrm{p}<0.05)$, neurological $(\mathrm{r}=-0.32 ; \mathrm{p}<0.05)$ and total $(\mathrm{r}=-0.39 ; \mathrm{p}<0.05)$ MSSI scores, and with ESS $(\mathrm{r}=-0.42 ; \mathrm{p}<0.001)$ and FSS $(\mathrm{r}=-0.38 ; \mathrm{p}<0.01)$ values. The MCS correlated significantly with FSS $(\mathrm{r}=-0.44 ; \mathrm{p}<0.05)$ and ESS $(\mathrm{r}=-0.42 ; \mathrm{p}<0.01)$ values and with age $(\mathrm{r}=-0.31 ; \mathrm{p}<0.05)$. On multiple stepwise regression analyses (table 2) ESS, age and the total MSSI values were independently associated with the PCS of the SF-36 data (corrected $\mathrm{R}^{2}=-0.323 ; \mathrm{p}<0.001$ ), and ESS and age explained a quarter of variance in MCS (corrected $\left.\mathrm{R}^{2}=-0.253 ; \mathrm{p}<0.001\right)$.

\section{Discussion}

The largest group of disorders causing daytime sleepiness consists of sleep-related disturbances of breathing, where neuroregulatory mechanisms play a major role in pathophysiology [7]. Recent studies demonstrated an association between change in white matter grade and measures of central sleep apnea that was consistent with a causal pathway in which central sleep apnea contributes to the progression of white matter disease [4]. As a structural basis, an affection of brain regions associated with autonomic and respiratory control - as they are classically represented in the brain stem - has been suggested [8].

In patients with $\mathrm{FD}$, cerebral vasculopathy as a result of progressive sphingolipid deposits in the vascular endothelium and vascular smooth muscle has been confirmed by neuropathologic, neuroradiologic and functional studies, and occurs frequently at a rather early age. Accordingly, cerebral WML are frequent findings in cranial MRI of FD patients [2]. In a brain-imaging study of $50 \mathrm{FD}$ patients, who had a mean age of 33 years, only $32 \%$ had no WML [9]. Additionally, early and widespread ultrastructural cerebral changes in FD patients have been detected using advanced MRI techniques such as diffusion tensor imaging $[2,10]$. Central sleep apnea due to cerebral vasculopathy might be the underlying pathomechanism of EDS in FD. Although one can only draw limited conclusions from one case report, our findings of a FD patient with severe EDS and confluent WML including the brain stem, but without renal or cardiac involvement, support this hypothesis and suggest that not only are cerebral white matter changes present in FD patients, but also that these may be relevant for the initiation of clinical symptoms.

With a frequency of $68 \%$, EDS exceeds the prevalence of other common symptoms of FD in our consecutively investigated patient group. Moreover, EDS significantly impairs QoL, independently of cardiac, renal or neurological involvement. Even though recurrent acroparesthesia, cerebrovascular events, hemodialysis or cardiac dysfunction could lead to some sleep disturbance, this would not explain the high prevalence rate of EDS. Additionally, we found no correlation between these symptoms and ESS scores.

Although chronic fatigue is a frequently reported symptom of patients with FD, this is the first study showing a high prevalence of EDS in this patient group. One reason for this might be that sleepiness and fatigue are conceptually distinct but pervasively confounded 
in research, clinical settings, and everyday spoken language. The pathophysiology of chronic fatigue remains unknown and many of the postulated etiologies of chronic fatigue syndrome affect sleep. Thus, EDS and fatigue have overlapping features, which can lead to imprecise diagnostic formulations and subsequent suboptimal intervention and management decisions. For example, it has long been known that fatigue, rather than sleepiness, is correlated with the experience of insomnia. Even patients with obstructive sleep apnea complain of fatigue, tiredness, and lack of energy [11]. Due to the relative dichotomy between sleepiness and fatigue and the underemphasis of fatigue as an independent consequence of sleep disorders by many health professionals, the specific daytime sleepiness features of sleep apnea are often not recognized, leading to underreferral for further diagnostic evaluation procedures. This may result in an underdiagnosis of sleep disorders, especially when fatigue rather than sleepiness is emphasized as the chief complaint.

Recent studies have indicated that patients with chronic fatigue had a very high incidence of previously undiagnosed primary sleep disorder such as sleep apnea/hypopnea syndrome $[12,13]$. They also had very high rates of self-reported insomnia and nonrestorative sleep. Additionally, narcolepsy and chronic fatigue patients were found to be similar on psychological adjustment [12]. These data support the hypothesis that primary sleep disorders in individuals with chronic fatigue are underdiagnosed in primary care settings. Although a significant portion of patients in this study reported pathological fatigue without overlap of sleepiness, only $9 \%$ reported pathological sleepiness without overlap of fatigue. Thus, it is tempting to speculate that a substantial part of FD patients suffers from undiagnosed EDS, potentially caused by a treatable primary sleep disorder, which confounded the explicit fatigue questionnaire. However, this is the first report addressing an association of EDS and FD and, therefore, we believe that this symptom may have been considerably underestimated in FD patients.

Since chronic fatigue syndrome is reported as a common symptom in various chronic diseases, such as malignant, infectious, neuromuscular, or rheumatologic disease, and since most studies have not explicitly considered a treatable primary sleep disorder when evaluating their patients, many of them may suffer from EDS rather than from chronic fatigue. Particularly patients with an involvement of the central nervous system, which is a frequent finding in many chronic diseases [14, 15], have an increased risk for sleeprelated breathing disorders. However, this assumption remains hypothetic, and formal polysomnographic sleep studies are required to examine this issue.

In conclusion, our results stress that EDS is a common and - in the present literature underdiagnosed symptom in FD patients, accompanied by a significant impact on QoL.

Further studies with a larger number of patients are needed to verify the frequency of EDS in patients with FD. Therefore, continuous polysomnographic recordings of FD patients are required, preferably in combination with cerebral MRI. With a view to the existing effective therapies of EDS due to nocturnal breathing disorders, and its enormous impact on QoL, clinicians should be aware of this symptom as an additional characteristic feature in FD patients. 


\begin{tabular}{l|l|l|l} 
Cose Reports in & $\begin{array}{l}\text { Case Rep Neurol 2009;1:33-40 } \\
\text { D0l: } 10.1159 / 000226792\end{array}$ & Published online: July 22, 2009 & $\begin{array}{l}\odot \text { 2009 S. Karger AG, Basel } \\
\text { ISSN 1662-680X } \\
\text { www.karger.com/crn }\end{array}$ \\
\hline
\end{tabular}

Table 1. Health-related quality of life in FD patients compared to a German reference population

\begin{tabular}{lllc}
\hline $\begin{array}{l}\text { SF-36 subscales and both } \\
\text { components }\end{array}$ & FD patients & $\begin{array}{l}\text { German reference } \\
\text { population* }\end{array}$ & p values \\
\hline Physical function & $64.8 \pm 28.2$ & $85.8 \pm 22.1$ & $<0.01$ \\
Physical role & $47.1 \pm 36.3$ & $83.7 \pm 31.7$ & $<0.01$ \\
Bodily pain & $63.2 \pm 27.9$ & $79.0 \pm 27.3$ & $<0.01$ \\
General health & $59.8 \pm 20.3$ & $68.1 \pm 20.1$ & $<0.01$ \\
Vitality & $42.6 \pm 22.5$ & $63.3 \pm 18.4$ & $<0.01$ \\
Social functioning & $66.3 \pm 24.7$ & $88.7 \pm 18.4$ & $<0.01$ \\
Emotional role & $81.8 \pm 34.3$ & $90.6 \pm 25.6$ & 0.06 \\
Mental health & $70.0 \pm 22.2$ & $73.9 \pm 16.3$ & 0.29 \\
Physical composite summary & $44.2 \pm 9.8$ & $50.2 \pm 10.2$ & $<0.01$ \\
Mental composite summary & $43.8 \pm 10.2$ & $51.5 \pm 8.1$ & 0.048 \\
\hline
\end{tabular}

* As reported in Bullinger [6] $(\mathrm{n}=2,911)$, measured by the SF-36-survey.

Table 2. Predictors of SF-36 physical and mental component scale

\begin{tabular}{llllll}
\hline Dependent variable & Covariants & Standardized $\beta \mathrm{T}$ & $\begin{array}{l}\text { Corrected } \\
\mathrm{R}^{2}\end{array}$ & $\mathrm{p}$ value \\
\hline Physical component scale & 1. ESS & -0.40 & -5.0 & & $<0.001$ \\
& 2. Age & -0.34 & -3.5 & & $<0.01$ \\
& 3. Total MSSI & -0.18 & -2.1 & -0.323 & $<0.05$ \\
Mental component scale & 1. ESS & -0.54 & -7.4 & & $<0.001$ \\
& 2. Age & -0.21 & -4.5 & -0.253 & $<0.01$ \\
\hline
\end{tabular}




\begin{tabular}{l|l|l|l} 
Cose Reports in & $\begin{array}{l}\text { Case Rep Neurol 2009;1:33-40 } \\
\text { D0l: } 10.1159 / 000226792\end{array}$ & Published online: July 22, 2009 & $\begin{array}{l}\text { @ 2009 S. Karger AG, Basel } \\
\text { ISSN 1662-680X } \\
\text { www.karger.com/crn }\end{array}$ \\
\hline
\end{tabular}

Fig. 1. Lower row: T2-weighted (3.0 Tesla; TR 4000/TE 120) sequences of cranial MRI of a FD patient show confluent bilateral white matter changes, significantly involving the brainstem (arrows). Upper row: Polysomnographic detail of the same patient shows a Cheyne-Stokes respiration characterized by oscillation of ventilation between central apnea and hyperpnea with recurring $\mathrm{O}_{2}$ desaturation.

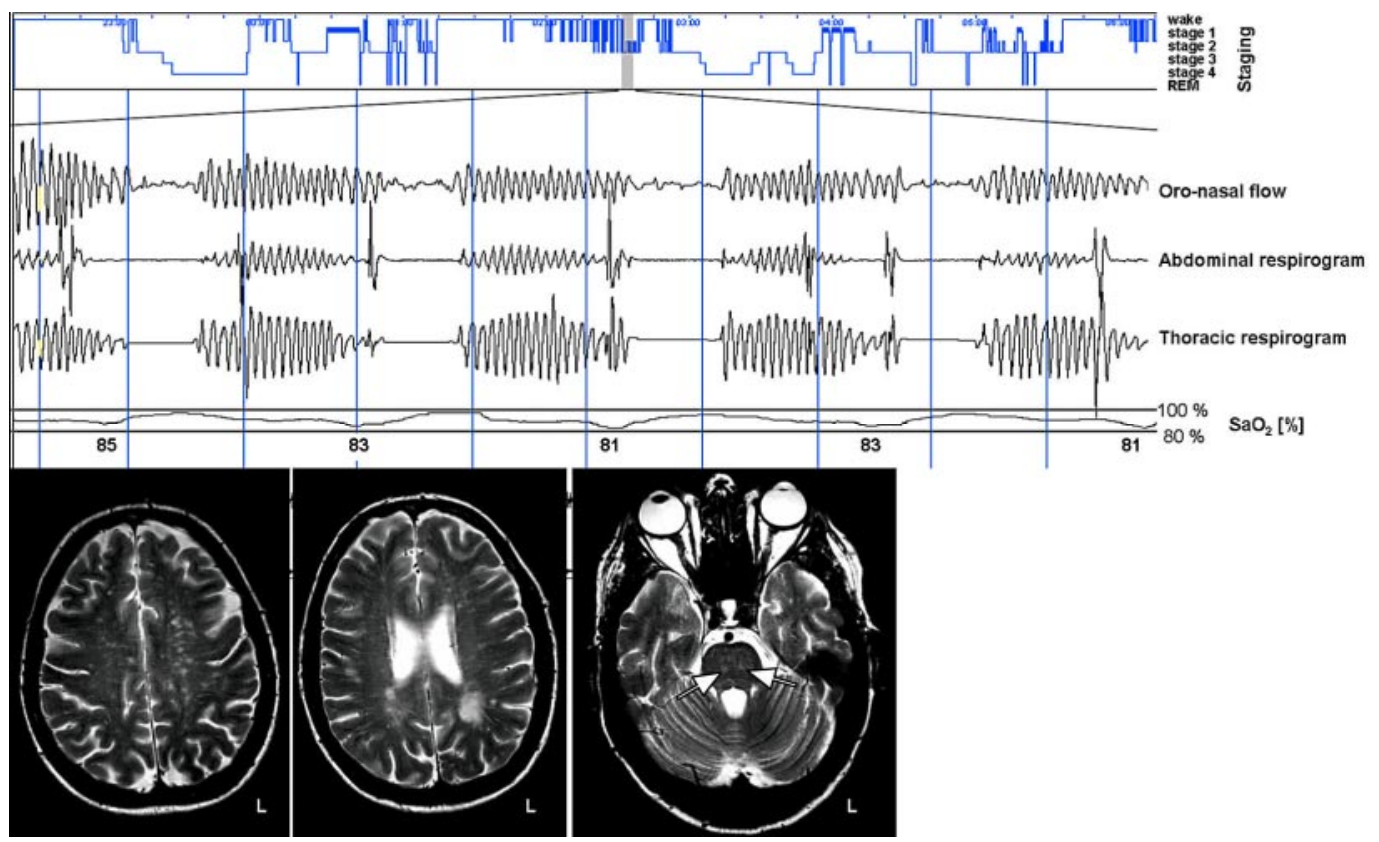

Fig. 2. Prevalence of symptoms and organ involvement in 49 FD patients. Prevalence of each symptom is expressed as percentage of the total number of patients. Excessive daytime sleepiness was the most common clinical symptom.

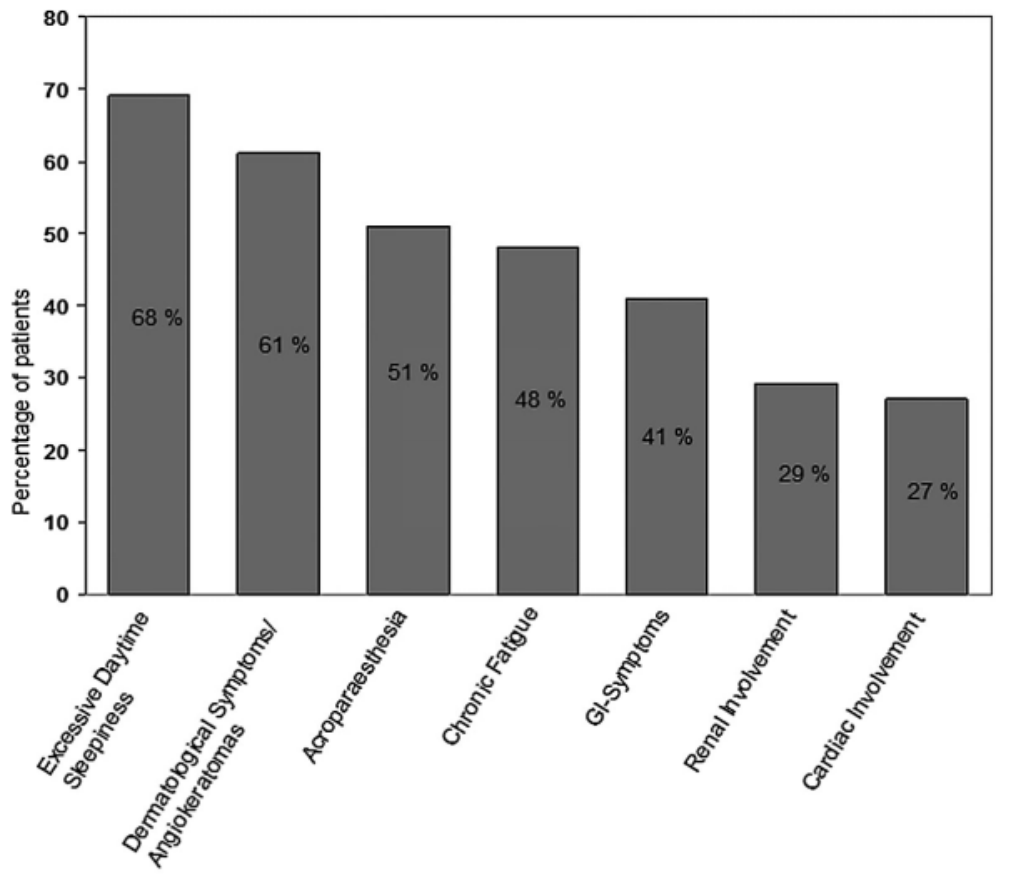




\begin{tabular}{l|l|l|l} 
Cose Reports in & $\begin{array}{l}\text { Case Rep Neurol 2009;1:33-40 } \\
\text { Dol: } 10.1159 / 000226792\end{array}$ & Published online: July 22, 2009 & $\begin{array}{l}\text { ○ 2009 S. Karger AG, Basel } \\
\text { ISSN 1662-680X } \\
\text { www.karger.com/crn }\end{array}$ \\
\hline
\end{tabular}

\section{References}

1 Desnick RJ, Brady R, Barranger J, Collins AJ, Germain DP, Goldman M, Grabowski G, Packman S, Wilcox WR: Fabry disease, an under-recognized multisystemic disorder: expert recommendations for diagnosis, management, and enzyme replacement therapy. Ann Intern Med 2003;138:338-346.

-2 Fellgiebel A, Muller MJ, Ginsberg L: CNS manifestations of Fabry's disease. Lancet Neurol 2006;5:791-795.

-3 Gold KF, Pastores GM, Botteman MF, Yeh JM, Sweeney S, Aliski W, Pashos CL: Quality of life of patients with Fabry disease. Qual Life Res 2002;11:317-327.

$\checkmark 4$ Robbins J, Redline S, Ervin A, Walsleben JA, Ding J, Nieto FJ: Associations of sleep-disordered breathing and cerebral changes on MRI. J Clin Sleep Med 2005;1:159-165.

-5 Whybra C, Kampmann C, Krummenauer F, Ries M, Mengel E, Miebach E, Baehner F, Kim K, Bajbouj M, Schwarting A, Gal A, Beck M: The Mainz Severity Score Index: a new instrument for quantifying the Anderson-Fabry disease phenotype, and the response of patients to enzyme replacement therapy. Clin Genet 2004;65:299-307.

6 Bullinger M: Assessment of health related quality of life with the SF-36 Health Survey (in German). Rehabilitation (Stuttg) 1996;35:XXVII-XXVII.

7 El Ad B, Korczyn AD: Disorders of excessive daytime sleepiness - an update. J Neurol Sci 1998;153:192-202.

8 Kumar R, Macey PM, Woo MA, Alger JR, Harper RM: Elevated mean diffusivity in widespread brain regions in congenital central hypoventilation syndrome. J Magn Reson Imaging 2006;24:1252-1258.

-9 Crutchfield KE, Patronas NJ, Dambrosia JM, Frei KP, Banerjee TK, Barton NW, Schiffmann R: Quantitative analysis of cerebral vasculopathy in patients with Fabry disease. Neurology 1998;50:1746-1749.

10 Albrecht J, Dellani PR, Muller MJ, Schermuly I, Beck M, Stoeter P, Gerhard A, Fellgiebel A: Voxel based analyses of diffusion tensor imaging in Fabry disease. J Neurol Neurosurg Psychiatry 2007;78:964-969.

11 Chervin RD: Sleepiness, fatigue, tiredness, and lack of energy in obstructive sleep apnea. Chest 2000;118:372-379.

12 Fossey M, Libman E, Bailes S, Baltzan M, Schondorf R, Amsel R, Fichten CS: Sleep quality and psychological adjustment in chronic fatigue syndrome. J Behav Med 2004;27:581-605.

13 Guilleminault C, Poyares D, Rosa A, Kirisoglu C, Almeida T, Lopes MC: Chronic fatigue, unrefreshing sleep and nocturnal polysomnography. Sleep Med 2006;7:513-520.

14 Chin RL, Latov N: Central nervous system manifestations of rheumatologic diseases. Curr Opin Rheumatol 2005;17:91-99.

-15 D’Angelo MG, Bresolin N: Cognitive impairment in neuromuscular disorders. Muscle Nerve 2006;34:16-33. 